\title{
Del malestar a la amenaza: La Sociedad de Fomento Fabril y el populismo ibañista, 1950 - $1953^{*}$
}

\author{
From discontent to threat: The Sociedad de Fomento Fabril and Ibáñez \\ administration, 1950 - 1953
}

\author{
Eduardo López Bravo**
}

\begin{abstract}
Resumen: Esta comunicación aborda el itinerario de transformaciones de las fuerzas de la producción industrial durante los años 1951 y 1953. En este período, asistimos a nivel nacional a una etapa marcada por la "transición" entre las formas de hacer política de los años cuarenta y el posterior clima político e ideológico de los años sesenta. En esta breve coyuntura, las fuerzas empresariales agrupadas principalmente, aunque no exclusivamente, en torno a SOFOFA, también experimentaron una fase de "transición" que las empujó a un proceso de cambios organizacionales que las condujo a la rearticulación de las organizaciones que representaban los intereses empresariales y, por otra parte, al cuestionamiento de su colaboración con el modelo de industrialización bajo la supervisión del Estado. En este contexto, el hito empresarial de la Convención Nacional de Industria de junio del año 1953 constituyó un punto de inflexión caracterizado por el "giro retórico-discursivo" de las fuerzas de la producción contra la naturaleza de la modernización capitalista implementada en Chile desde 1939. En el cuadro de incertidumbre y amenaza que abrió el intervencionismo estatal propiciado por el populismo ibañista, el torneo industrial puso en evidencia al interior de SOFOFA un duro debate y conflicto generacional entre aquellos que proponían un modo de acción político empresarial más enérgico frente al poder político y aquellos deseaban continuar con el lobby y los métodos de persuasión corporativista informales con autoridades y parlamentarios.
\end{abstract}

Palabras Clave: Populismo, Empresarios, SOFOFA, Industrialización.

\begin{abstract}
This article analyses the organizational and political changes experienced by SOFOFA, the Chilean industrialist main organization. In a time span characterized by growing confrontational politics, the industrialist also implemented organizational changes in SOFOFA and engaged in a prolonged and profound debate about their relationship with the public sector. The III Industry National Conference, organized by SOFOFA and held in June 1953, marked a turning point. It signaled a much more
\end{abstract}

\footnotetext{
* Esta comunicación es parte del Proyecto FONDECYT No 1150819 "El itinerario del proyecto monetarista chileno (19521975)" dirigido por el Ph., D. Luis Ortega Martínez. Agradecimientos a Maximiliano Ortega Valenzuela como Asistente de Investigación por su generoso aporte y comentarios.

** Magister en Historia de América. Candidato a Doctor en Historia en Estudios Americanos. Instituto de Estudios Avanzados (IDEA), Universidad de Santiago de Chile. E-mail: eduardolopezb@yahoo.es
} 
critical stance towards the model of capitalist modernization since 1939. Propelled by the uncertainty and the threat unleashed by the economic interventionism of the second Ibáñez administration (1952-1958), the conference brought to the fore the disagreements and the generational conflict between those members who wanted a more vigorous entrepreneurial position vis-à-vis the authorities and those who preferred to maintain the traditional lobbying methods and informal corporatist arrangements with government officials and congressmen.

Keywords: populism, Businessmen, SOFOFA, industrialization

\section{Introducción: El problema global}

Los años cincuenta pusieron en evidencia los límites de lo que Boltansky y Chiapello describieron para los años treinta como la "era del Intervencionismo"1. En efecto, el capitalismo supervisado por el Estado en el período de post guerra fue progresivamente impugnados por los intereses empresariales globales, generando (tempranamente) las condiciones para la futura "ofensiva neoliberal" de los años setenta. ${ }^{2}$ En el ámbito nacional, el descenlace del ciclo del radicalismo y el segundo gobierno de Carlos Ibáñez del Campo puso en evidencia que la estrategia de crecimiento económico implementada desde fines de la década de 1930 se había agotado. ${ }^{3}$

Respecto de la reacción de las fuerzas de la producción en esta coyuntura existen algunas divergencias. Para algunos historiadores, las influencias empresariales en el aparato del Estado se vieron seriamente afectadas. Desde esta perspectiva, el rumbo que tomó el gobierno de González Videla en su etapa final y, especialmente, el carácter populista del movimiento ibañista constituyeron serios obstáculos para que el empresariado ejerciera influencia directa sobre el gobierno como era ya tradición durante las administraciones radicales. Incluso, aun cuando lograrán revertir políticas que los afectaban, no podían estar

\footnotetext{
${ }^{1}$ Luc Boltanski y Eve Chiapello. El Nuevo Espíritu del Capitalismo. Ediciones Akal, S.A. 2002. Como sostienen los autores, la "era del Intervencionismo", es entendida como un tipo de modernización capitalista donde las relaciones entre las empresas, la fuerza laboral y los gobiernos funcionaron en marcos de colaboración a través de instituciones que no necesariamente fueron de mercado.

2 Tomás Undurraga. Divergencias. Trayectorias del neoliberalismo en Argentina y Chile, Santiago, Ediciones Universidad Diego Portales, 2014, p. 26

${ }^{3}$ Respecto de los efectos económicos de la segunda administración de Ibáñez véase a Ricardo Ffrench-David. Chile, entre el neoliberalismo y el crecimiento con equidad. Cuarenta años de políticas económicas y sus lecciones para el futuro. JC Sáez Editor SPA., Santiago, 2014 (Quinta Edición). Tomás Moulian. El Gobierno de Ibáñez, 1952- 1958. Material docente sobre historia de Chile. Programa Flacso - Santiago de Chile No 2. Enero, 1986.
} 
seguros por cuánto tiempo se mantendrían las decisiones que había adoptado el gobierno. ${ }^{4}$ Otros trabajos han argumentado que la agudización de los problemas históricos en los ámbitos económico y social durante la década de los cincuenta; es decir, la inflación y el bajo crecimiento, la caída de los salarios reales y desempleo, fueron factores que se tradujeron en incertidumbre e incluso se temió el cierre del sistema democrático por parte de sectores del empresariado y la derecha política. ${ }^{5}$ Desde otro punto de vista, se ha sostenido que la primera etapa del gobierno de Ibáñez fue percibido por los empresarios con temor. Específicamente, el plan de "emergencia económica" que el Ministro de Hacienda Felipe Herrera implementó durante los meses de abril - septiembre 1953, cuyos objetivos consideraron el control de precios y el control estatal del comercio, despertaron fuertes resistencias empresariales. ${ }^{6}$ Una mirada analítica tributaria de las ciencias políticas manifiesta que el ibañismo fue percibido como una "amenaza" para las fuerzas productoras del país. En esta perspectiva, Ibáñez configuró esta percepción fruto de su carácter populista y la heterogeneidad de la coalición política que lo acompañó. ${ }^{7}$

Los trabajos de Sofía Correa, Verónica Valdivia y Manuel Gárate han contribuido al debate sobre la participación del mundo empresarial en dos coyunturas relevantes y cuyos resultados fue impulsar estrategias alternativas a la crisis del modelo de crecimiento económico. En primer lugar, el convenio entre la Facultad de Ciencias Económicas de la Universidad Católica de Chile y el Departamento de Economía de la Universidad de Chicago que comenzó a ser negociado en 1955. En segundo lugar, la contratación, a instancias del grupo empresarial El Mercurio, de la Misión Klein-Saks en el mismo año. ${ }^{8}$ Como sostiene Luis Ortega, ambos hitos marcaron el arranque político e intelecctual del monetarismo en el país; sin embargo, se encuentra pendiente el estudio de los actores individuales $y$ colectivos que dieron contenido e impulso a este itinerario de transformaciones. ${ }^{9}$

Sin tratarse de tesis erróneas, estas perspectivas analíticas deben ser complementadas, pues ellas no consideran en toda su dimensión el comportamiento político de los gremios empresariales y las relaciones con el Estado y la política. En este artículo sostenemos que los primeros años de la década de los cincuenta mostró en toda su dimensión el comportamiento político de los gremios empresariales cuando enfrentan contextos de incertidumbre, malestar y amenaza. En la coyuntura que revisamos, los gremios

\footnotetext{
${ }^{4}$ Sofía Correa. Con las riendas del poder. La derecha chilena en el siglo XX. Random House Mondadori S.A. Santiago de Chile, 2011. Marcelo Cavarozzi. The government and the industrial bourgeosie in Chile: 1938 - 1964. University of California, 1975.

5 Juan Pablo Couyoumdjian. “¿Por qué la misión Klein Saks? Los orígenes de un programa de estabilización económica para Chile" en Juan Pablo Couyoumdjian (Editor). Reformas económicas e instituciones políticas: la experiencia de la misión Klein Saks en Chile. Universidad del Desarrollo, Santiago, 2011.

${ }^{6}$ Tomás Moulian. El gobierno... op. cit., pp. $28-30$.

7 Véase Pablo Rubio y Xaviera Salgado. "Gremios empresariales y derecha chilena: Redes de poder y propuestas programáticas de la Sociedad Nacional de agricultura, 1952 - 1958” Les Cahiers ALHIM. Partis, mouvements et organisations patronales: les droites dans le Cone Sud Latino- américain (1950 - 2016). № 32, 2016.

${ }^{8} \mathrm{Al}$ respecto véase, Verónica Valdivia. Nacionales y gremialistas. El "parto" de la nueva derecha política chilena 1964 1973. Santiago, LOM, 2008; Sofía Correa, op. cit.; Manuel Gárate. La revolución capitalista de Chile (1973 - 2003. Universidad Alberto Hurtado. Santiago de Chile, 2012.

${ }^{9}$ Luis Ortega Martínez. "La nueva SOFOFA y los orígenes del gremialismo empresarial, 1953 y 1957”. Inédito.
} 
empresariales debieron enfrentar un escenario adverso como grupo de interés. En efecto, las transformaciones políticas, los poderes públicos y las fuerzas sindicales cuestionaron crecientemente los pilares en que se funda la empresa privada: el derecho de propiedad; la seguridad jurídica; la libertad económica y la autoridad en la empresa. ${ }^{10}$

La dinámica política y económico social de los años cincuenta crearon las condiciones para la impugnación de la clase empresarial al capitalismo supervisado por el Estado. En adelante, las asociaciones gremiales junto con el apoyo técnico de asesorías norteamiericanas se vincularan de diversa forma e intensidad en espacios empresariales y académicos para elaborar un programa político alternativo a la crisis integral de la economía y redefinir un nuevo liderazgo y estrategia empresarial para impulsar el desarrollo. $^{11}$

Para redactar este trabajo hemos revisado fuentes documentales y periódicos. En relación a las primeras, están constituidas por las Actas del Consejo Directivo y las Juntas Generales de Socios de SOFOFA. Estas fueron publicadas en la revista gremial "Industria". Los períódicos consultados fueron El Mercurio y El Debate. Además, se ha revisado la revista Industria y Panorama Económico. De esta manera, hemos podido reunir el material suficiente para reconstruir el proceso histórico que nos proponemos relatar.

\section{El malestar y el conflicto generacional al interior de SOFOFA}

Con ocasión de la $67^{\mathrm{a}}$ Junta General Ordinaria de Socios de la Sociedad de Fomento Fabril (en adelante SOFOFA), en enero de 1951, y cuando habían concluido los discursos que Walter Müller y Jorge Alessandri, Domingo Arteaga Infante solicitó la palabra para manifestar que:

“[...] merecen elogios el discurso del señor Müller y el llamado hecho por el señor Alessandri, y también acepto el aumento de la cuota social, pero sí con la condición de que las entidades patronales cambien de política: que haya más energía para defender los justos intereses de los industriales y menos banquetes y discursos y contemporización con el Presidente de la República y los Ministros de Estado. $[\ldots]^{\prime \prime} 12$

Haciendo uso del derecho a réplica, el presidente de SOFOFA volvió a destacar en los evidentes beneficios de las tácticas de convergencia y lobby que realizaba habitualmente la Sociedad con las autoridades y los parlamentaros.

"[...] si los socios se tomaran la molestia de leer la revista "INDUSTRIA" que se

\footnotetext{
${ }^{10}$ Genaro Arriagada. Los empresarios y la política. LOM Ediciones. Santiago de Chile, 2004. pp. 94 - 95.

${ }^{11}$ Coincidimos con autores cómo Juan Gabriel Valdés, Sofía Correa, Manuel Gárate, Luis Ortega y Joaquín Fernández Abara, quienes sostienen que la década de 1950 constituye la etapa de recepción de ideas monetaristas, principalmente a través de transferencias ideológicas desde Estados Unidos y la adopción de un nuevo programa alternativo al del capitalismo estatal desarrollista, en los que radicarían los antecedentes del proyecto neoliberal chileno. Véase Ortega, Luis, "Las operaciones ideológicas y políticas en la construcción de un nuevo proyecto económico (y social) para Chile, 1950-1970", Revista Espacio Regional, vol. XI, n 11, 2015; Ortega, 2015; Gárate, op. cit.; Correa, op. cit., y Juan Gabriel Valdés. La Escuela de Chicago: Operación Chile. Buenos Aires, Grupo Zeta, 1989.

${ }^{12}$ Industria. Boletín de la Sociedad de Fomento Fabril. No 2. Año LXVII. Febrero, 1951. p. 115.
} 
reparte mensualmente, estarán al corriente de la acción constante que desarrolla la Sociedad durante todo el año, ante el Gobierno y el Parlamento. Por otra parte, la acción directa y enérgica no es tan fácil como el señor Arteaga se la imagina [...]" 13

Se enfrentaban tempranamente al interior de la entidad gremial dos maneras de concebir las relaciones entre los industriales y el poder político. En un extremo, los tradicionales liderazgos de Walter Müller ${ }^{14}$ en SOFOFA y de Jorge Alessandri ${ }^{15}$ en la Confederación de la Producción y el Comercio (en adelante CPC), quienes fueron partidarios de continuar recurriendo a las tácticas flexibles que habían utilizado tradicionalmente en otros períodos relativamente ásperos para el mundo empresarial. ${ }^{16}$ los contactos personales con altos funcionarios administrativos y políticos en el congreso, alentaron las acciones de organizaciones públicas "amigables" y atacaron selectivamente las organizaciones o funcionarios públicos "hostiles". ${ }^{7}$

Paralelamente, un grupo de jóvenes empresarios aglutinados en su mayoría en ASIMET, abogaron por una defensa de los intereses de los industriales más confrontacional respecto del gobierno y de los poderes políticos. Estos nuevos liderazgos empresariales, cuestionaron crecientemente los resultados concretos de las tácticas de moderación de la dirigencia tradicional y postularon el reforzamiento de la presencia pública de los empresarios mediante acciones más enérgicas respecto del gobierno de turno. En palabras de Domingo Arteaga, “[...] Es necesario que tengamos plena conciencia del poder económico que representamos y, por consiguiente, podemos luchar de igual a igual con los poderes públicos [...]" 18

Se trató de una nueva generación de empresarios que se formaron como empresarios después de la depresión de los años treinta. Entre ellos destacaron los dirigentes de la Asociación de Industriales Metalúrgicos de Chile (ASIMET), como Eugenio Heiremans

\footnotetext{
${ }^{13}$ Ibíd.

${ }^{14}$ Walter Müller Hess. Presdente de SOFOFA entre 1935 - 1955. Figura relevante de los empresarios industriales por tres décadas. Fue uno de los principales gestores y defensores de las políticas económicas implementadas a través de CORFO, al mismo tiempo que privilegió como presidente de SOFOFA una política de colaboración con el Estado, tanto a través de contactos personales y en la participación como representantes de la sociedad en organismos públicos.

15 Jorge Alessandri Rodríguez (1896 - 1986). Importante político, empresario y dirigente gremial que se desempeñó como Presidente de la República entre 1958 - 1964. Entre 1926 y 1932 fue electo diputado por Santiago, para luego ser presidente de la Caja de Caja de Crédito Hipotecario entre 1932 y 1938. Tras el triunfo de Pedro Aguirre Cerda, se dedicó a la actividad empresarial como presidente de la Compañía Manufacturera de Papeles y Cartones (CMPC). En el gobierno de Gabriel González Videla, fue designado ministro de Hacienda entre 1947 y 1950. En 1944 fue elegido presidente de la Confederación de la Producción y el Comercio cargo que debió dejar en 1947 para reingresar a la política. En 1950 reasume la presidencia de la CPC hasta 1957. En 1957 fue electo Senador por Santiago. http://www.memoriachilena.cl/602/w3-article-3470.html. visitado el 13 de marzo 2017.

16 Reforzaban estas acciones los vínculos institucionales formales la presencia del presidente de SOFOFA en los directorios del Banco Central; en el Consejo Directivo de CORFO; en el Consejo de Economía Nacional; en la Comisión Nacional de Petróleo y en la Comisión de Establecimiento de Industrias del Ministerio de Economía y Comercio. Véase boletín Industria. Boletín de la Sociedad de Fomento Fabril. № 1. Año LXVII. Enero, 1951. p. 5.

${ }^{17}$ Cavarozzi, op. cit., p. 248; Cecilia Montero. La revolución empresarial chilena.Cieplan/Dolmen Ediciones. pp. 97 - 98.

${ }^{18}$ Industria. Boletín de la Sociedad de Fomento Fabril. No 2. Año LXVII. Febrero, 1951. p. 115.
} 
Despouy (S.A. Heiremans "Socometal")" ${ }^{19}$, Ernesto Ayala ${ }^{20}$, Fernando Smith, Hernán Briones $^{21}$ y Domingo Arteaga Infante (Fábricas Arteaga Ltda.) ${ }^{22}$, quienes manifestaron abiertamente diferencias con el estilo de conducción de SOFOFA y CPC en los últimos 15 años de aplicación del modelo de industrialización bajo supervisión estatal.

¿Cómo comprender el protagonismo de ASIMET y el motivo de las críticas gremiales y políticas a la conducción de SOFOFA y la CPC? En primer término, desde mediados de la década de 1940 y, especialmente, a inicios de los años cincuenta, la industria metalúrgica chilena alcanzó el primer lugar entre las actividades fabriles del país tanto por el número de obreros y empleados que en ella se desempañaban como por el monto de capitales invertidos en esta actividad. ${ }^{23}$ En segundo lugar, se trató del principal gremio industrial con productos elaborados para la exportación del país en base a minerales como cobre, acero y fierro fundido. ${ }^{24}$ Finalmente, y a diferencia de las industrias tradicionales, la viabilidad de la industria del metal dependía directamente de la promoción estatal del comercio exterior; fuese indirectamente a través de las licencias de importación y tarifas protectoras, o directamente, a través de los créditos industriales financiados por el Estado. ${ }^{25}$ En todas las

\footnotetext{
${ }^{19}$ Eugenio Heiremans Despouy (1923 - 2010). Empresario y dirigente empresarial dos veces presidente de SOFOFA y máximo líder de Asociación de Industriales Metalúrgicos de Chile (ASIMET). Al hacerse cargo de la empresa de su padre (Socometal), se preocupó de tomar cursos de administración en Estados Unidos y Europa. Creador del sistema mutual chileno mediante la Asociación Chilena de Seguridad (Achs), conformó junto a Hernán Briones y Ernesto Ayala el grupo de "Los Tres Mosqueteros", cercano al gobierno de facto del General Augusto Pinochet y defensor del libre mercado. También contribuyó al desarrollo industrial, a la integración económica con Argentina y la creación de ICARE. Complementó su actividad como presidente de la asociación con otros cargos, tales como director de CMPC, Indura, Megavisión, CEP, Universidad Bernardo O'Higgins y la Corporación Patrimonio Cultural de Chile. Se desempeñó como director de la Fundación Jorge Alessandri Rodríguez y de la Fundación Hernán Alessandri Rodríguez. El Mercurio. 18.12.2010. Cuerpo Economía y Negocios.

${ }^{20}$ Ernesto Ayala Oliva (1916 - 2007). Su padre (Ernesto Ayala Schlegel) fue un ingeniero civil e historiador de vocación que publicó la "Historia de la Ingenieria" en 1938. En 1939 se titulo de Ingeniero Civil en la Universidad de Chile. Realizó su práctica profesional en la CMPC de Puente Alto. Curso un postgrado de Ingeniería Eléctrica en Estados Unidos. Trabajó en el Ministerio de Obras Públicas, en CORFO y asumió como gerente general de FENSA. Fue presidente de ASIMET entre 1952 y 1954. Accionista de Indura, creada en 1948, con sus amigos de toda la vida: Eugenio Heiremans y Hernán Briones (los llamados tres mosqueteros), además de Eduardo Campino y Mario Vignola. Reemplazó a Jorge Alessandri como gerente general de la CMPC en 1957 hasta el año 1981. Presidente del directorio de la CMPC hasta 2002. Se desempeñó como presidente de SOFOFA entre 182 y 1987. Véase, Manuel José Gamonal. Ernesto Ayala Oliva. Constructor del progreso. Aguilar Chilena de Ediciones S.A. Santiago de Chile, 2012.

${ }^{21}$ Hernán Briones Gorostiaga (1913 - 2005). Estudió ingeniería en la Universidad de Chile y un postgrado en la Universidad de Charlottenburgo, en Berlín. Como representante de una empresa norteamericana, Briones puso las líneas para los primeros trolebuses que circularon en Santiago. En 1944, creó su primera empresa, "H. Briones". El holding de la Familia Briones, incluye negocios que van desde el cemento, a través de Empresas Bío Bío, hasta Porcelanas Florencia, pasando por la industria de gas comprimido. Ellas dan empleo a unas 4.000 personas. Presidente de SOFOFA entre 1991 y 1993, fue nombrado Consejero Honorario del gremio empresarial en junio de 1994. En 1995, presidió el directorio de la Fundación Pinochet. El año 2004, presentó su libro "90 años de historia", una especie de autobiografía, cuyo prólogo lleva la firma de Augusto Pinochet.

${ }^{22}$ Domingo Arteaga Infante. Ingeniero Químico graduado en la Universidad de Michigan en 1923, The Michigan Alumnus, Vol. XLIX, No 14, 06.02.1943. En 1933 estableció la Fábrica Arteaga Limitada elaboradora de productos químicos. Profesor de Química Industrial en la Universidad Católica; Referencia extraída desde el sitio Web: http://diccionariobiograficodechile.blogspot.cl/search?q=Domingo+Arteaga, visitado el 3 de diciembre 2016.

${ }^{23}$ Industria. Boletín de la Sociedad de Fomento Fabril. No 3, Año LXX, marzo, 1953. p. 243. "Nota de la Asoc. De Industriales metalúrgicos al Sr. Ministro de Economía y Comercio".

${ }^{24}$ Industria. Boletín de la Sociedad de Fomento Fabril. № 3, Año LXX, marzo, 1953. p. 244.

${ }^{25}$ Cavarozzi, op. cit., p. 249.
} 
decisiones relacionadas con la definición de los impuestos a la exportación e importación de mercaderías, las industrias metalúrgicas fueron los principales incumbentes.

En marzo de 1953, Ernesto Ayala Oliva, expuso lo que consideró el papel que la asociación metalúrgica cumplía en la coyuntura que vivía el país:

"[...] Podemos exhibir con orgullo a nuestras visitas de esta noche y al país en general la organización que reúne todos los metalúrgicos de Chile. Hemos sido calificados, y lo seremos por largo tiempo -así lo espero- como el grupo patronal gremial más agresivo; siempre en el campo de lo útil al país, y más lleno de vida y entusiasmo para trabajar en defensa de los legítimos derechos de la industria chilena $[\ldots] " 26$

\section{La amenaza populista de Ibáñez}

La situación preelectoral 1950 - 1952 fue paradojal. Mientras los indicadores económicos del período mostraban una fase de estabilidad y crecimiento, el clima ideológico evidenciaba una sensación de desencanto y frustración con los partidos políticos y las formas de hacer política. Lo anterior es relevante, pues, el fenómeno del ibañismo durante la campaña presidencial y su posterior triunfo electoral no es resultado del deterioro de la situación económica de la población.

Una breve mirada a los principales índices económicos muestra que el Producto Geográfico Bruto (PGB) en el quinquenio 1950 - 1953 alcanzó al 6,1\%, mostrando desempeños bastante más elevados que los resultados que entregó el período 1945-1950 que fue tan sólo del 3,0\%. En cuanto a las cifras de inflación, los indicadores tampoco eran especialmente preocupante. En efecto, el año 1948 alcanzó al 16,82\%, subiendo al 20,60\% en 1949 luego disminuir en 1950 en 16,51 para volver a subir al 23,39\% en 1951. El año 1952 la inflación disminuyó notablemente al 12,02\%. Por lo tanto, si bien el trienio 1949 - 1951 señalaba alzas de precios preocupantes, estas no anunciaban una tendencia al alcista. ${ }^{27}$ Ahora bien, entre 1949 y 1952 el sueldo vital aumentó más que el costo de la vida. Por ejemplo, en 1949 el sueldo vital alcanzó a21,05\%, el año 1950 subió al 25\% y en 1951 disminuyó levemente al 22,9\%. ${ }^{28}$ En opinión de Aníbal Pinto, el oleaje inflacionario no adquirió proporciones amenazantes sino hasta $1954 .^{29}$

Por tanto, el "terremoto ibañista" del año 1952 se explica por un clima ideológico y político previo marcado por el desencanto y la frustración. Se trató de un desencanto cuyo origen se asoció a las formas de hacer política y, principalmente, por las zigzagueantes políticas económicas del radicalismo entre 1944 y 1951. En este sentido, la opinión pública observó crecientemente que la aplicación de programas sociales y económicos redistributivos eran

\footnotetext{
${ }^{26}$ El Mercurio. 28.03.1953. p. 17. Cuerpo 2: “Asociación de Industriales Metalúrgicos agasajo al señor Eugenio Heiremans"

27 José Díaz, Rolf Lüders y Gert Wagner. Chile 1810 - 2010. La República en cifras. Historical Statistics. Ediciones Universidad C atólica de Chile. Santiago, 2016. p. 374.

${ }^{28}$ Panorama Económico. 22.05.1952. № 100. p. 279. Cifras obtenidas de la CORFO, sección estudios.

${ }^{29}$ Aníbal Pinto. Chile, un caso de desarrollo frustrado. Editorial Universitaria S. A., 1973. pp. 206 - 207.
} 
reemplazos en corto tiempo por propuesta de estabilización de derecha. ${ }^{30}$

Como ha sostenido Joaquín Fernández Abara, la campaña ibañista de 1952 se caracterizó por un moralismo mesiánico, nacionalista y anti oligárquicos ajenos al tradicional juego partidista. Su programa, fruto de un proceso largo y tedioso, se orientó en un afán democratizador y manteniendo en el plano económico una política de fomento al desarrollo nacional bajo el rol planificador del estado. Dentro de esta mirada crítica anti oligárquica y antigobiernista, el ibañismo identificó al candidato empresarial Arturo Matte como parte de la "reacción plutocrática", responsable de corromper la "conciencia pública" mediante el cohecho. ${ }^{31}$.

Arturo Matte fue el más genuino representante del mundo empresarial tradicional. Integrante del clan familiar Alessandri, destacó por una breve trayectoria política. Ministro de Hacienda del presidente Juan Antonio Ríos entre el 1 de septiembre de 1943 hasta el 6 de octubre de 1944 fue también Senador por Santiago entre 1949 y 1957. Operador político y consejero de los presidentes de la República Arturo y Jorge Alessandri, respectivamente su suegro y cuñado. Sin embargo, la mayor parte del tiempo la dedico al mundo de los negocios y las organizaciones patronales. ${ }^{32}$ La candidatura de Matte se transformó en la opción que establecía puentes entre las redes de la derecha política y los gremios empresariales, representando la transición en la Derecha por figuras que mostraran trayectoria empresarial y vinculación política. Matte fue la perfecta combinación de ambas aspiraciones.

Tanto el grupo empresarial El Mercurio como SOFOFA no demoraron en tomar partido por su candidatura. En la editorial de julio de 1952, El Mercurio alertaba del peligro que enfrentaban las libertades políticas y económicas en la elección de septiembre:

“[...] En la elección presidencial del 4 de septiembre próximo se enfrentan una vez más estos conceptos primarios de la asociación política en una lucha tal vez decisiva para la nacionalidad [...] Las doctrinas que procuran amenguar o extinguir la libertad económica llevan, aun cuando no lo confiesen, a sofocar la libre iniciativa de los hombres y a convertir a éstos en minúsculos rodamientos de un aparato estatal gigantesco. Contra esta pretensión que niega los fueros de la persona humana, arrasa el criterio de libertad asentado en las costumbres de todos los chilenos y frustra el ordenado disfrute de lo que cada uno ha granjeado en la lucha económica, se alza incontenible la opinión pública independiente, formada en las

\footnotetext{
30 Tomás Moulian. Fracturas. De pedro Aguirre Cerda a Salvador Allende (1938 - 1973). LOM Ediciones. Santiago, 2014. p. 152.

${ }^{31}$ Joaquín Fernández Abara. El ibañismo (1937-1952): Un caso de populismo en la política chilena. Instituto de Historia Pontificia Universidad Católica de Chile. Santiago de Chile, 2007. pp. 181 - 190.

${ }^{32}$ Arturo Matte Larraín (1893 - 1980), abogado, educador (Sociedad de Instrucción Primaria) y empresario chileno. Presidente de la Compañía de Acero del Pacífico (CAP); gerente de la Sociedad de la Renta Urbana Pasaje Matte y gerente de la Sociedad Agrícola Trinidad S.A, Limache; presidente de la sociedad Portal Fernández Concha; director de Sederías Chile, Sumar S.A., y de la Organización Kappés; Consejero de la Caja de Seguro Obrero (más tarde se denominó Servicio de Seguro Social), Consejero de la Compañía de Petróleos de Chile (COPEC); Consejero de la Compañía Manufacturera de Papeles y Cartones; Presidente del Banco Sud Americano y Presidente de la Sociedad Productora de Papeles; Director de la Sociedad Cerámica Carrascal y Presidente de Viñas Chile S.A. Reseñas Biográficas Biblioteca del Congreso de Chile.
} 
lides del trabajo y dotada de iniciativa, voluntad y energía propia [...]". ${ }^{33}$

En sus memorias políticas, Arturo Olavarría Bravo exponía con claridad las expectativas de un electorado volátil y díscolo en el proceso eleccionario de 1952. La sociedad chilena, en su opinión, buscaba un cambio político para mejorar sus condiciones de vida y el liderazgo de una figura presidencial autoritaria.

“[...] Con cualquiera de ellos (Matte y Alfonso), seguiría el espectáculo vergonzoso de los parlamentarios dedicados exclusivamente a sus prebendas y negociados y, como el presidente constitucional necesitaría sus votos en el Congreso para poder gobernar, tendría que encubrirlos, y todo seguiría igual.

El señor Ibáñez, sí. A la menor dificultad, a la menor obstrucción de alguna iniciativa de bien público, clausuraría el Congreso, le colocaría la histórica herradura y mandaría a pasear a las islas inhóspitas a los señores parlamentarios de la oposición $[\ldots]^{33}$

El propio Arturo Matte señaló respecto del proceso eleccionario y la figura de Carlos Ibáñez del Campo su evaluación sobre los resultados electorales en 1952: "todos se equivocan con él. Sus adversarios lo creían un idiota, y estaban profundamente equivocados. Sus amigos lo consideraban incapaz de cualquier picardía, y tampoco era así. ¿Qué por qué me ganó a mí? Porque el país estaba hambriento de autoridad, creyó más en la firmeza de un militar que de un civil”. ${ }^{35}$

En este clima político y electoral, ¿cuál fue la posición que las fuerzas de la producción adoptaron frente al triunfo electoral de Carlos Ibáñez del Campo? Varias son las respuestas tentativas. En primer lugar, la coalición que acompañaba al candidato Carlos Ibáñez despertó incertidumbre en los hombres de negocios. El "general de la esperanza" apareció disfrazado de nuevo izquierdista y apoyado por una coalición política heterogénea que incluía a Socialistas Populares, Agrario Laboristas e independientes. Especial preocupación constituyó el apoyo del Partido Socialista Popular, quienes apostaban por el populismo como alternativa de alianza política para enfrentar a radicales y comunistas. Como destaca Cavarozzi, cuatro fueron sensibilidades políticas en disputa dentro del gobierno. Por una parte, aquellos proclives al entendimiento con la derecha política y el mundo empresarial para promover políticas antiinflacionarias. Un segundo grupo (Partido Socialista Popular) propusieron transformar el éxito electoral de Ibáñez en un movimiento de clase obrera. En tercer lugar, un sector liderado por el Partido Agrario Laborista que aspiró a crear un movimiento populista. Finalmente, quienes pretendía un populismo de carácter autoritario. 36

En segundo término, el programa de gobierno. En opinión de El Mercurio, el camino que proponía Ibáñez "está señalado por la línea económica estatista de intervención

\footnotetext{
${ }^{33}$ El Mercurio. 26.07.1952. p. 3. Editorial: "Libertades políticas y libertades económicas".

34 Arturo Olavarria Bravo. Chile entre dos Alessandri. Memorias políticas. Tomo II. Editorial Nascimento. Santiago, 1962. p. 121

35 Sociedad de Instrucción Primaria (Editor.) Arturo Matte Larraín. Un hombre de excepción. Editorial Universitaria. Santiago de Chile, 1980. p. 21.

${ }^{36}$ Cavarozzi, op. cit., pp. $220-221$.
} 
gubernamental sobre todos los procesos de la producción y el comercio"37. La propuesta ibañista era mucho más que eso: asumía un carácter "nacional-popular", siguiendo la moda del peronismo. Entre las principales medidas se encontraba la derogación de la Ley de Defensa de la Democracia, el rechazo del pacto militar con Estados Unidos, la reforma electoral y el desarrollo orgánico del movimiento popular. En tercer lugar, el impacto del resultado electoral. El general Ibáñez obtuvo el 46,79\% de los votos. El abanderado de la derecha y la clase empresarial, Arturo Matte Larraín, alcanzó el 27,81\% de los sufragios. El candidato radical, Pedro Enrique Alfonso, sufrió un sería derrota con tan sólo el 19,95\% de las preferencias. Por último, el candidato testimonial del Partido Socialista, Salvador Allende, con el 5,45\% del electorado. ${ }^{38}$

Finalmente, los primeros 120 días de gobierno ibañista fueron decisivos. En este período, el gobierno de Ibáñez solicitó al Parlamento Facultades Extraordinarias para implementar reformas económicas que incluían: a) controlar el mercado crediticito y la política monetaria mediante la creación del Banco del Estado; b) aumento de las atribuciones del Banco Central para controlar el crédito; c) creación de INACO para controlar el comercio interno; d) la creación de la Superintendencia de Abastecimientos de Precios; y e) fortalecer la organización de los trabajadores, política impulsada por el Partido Socialista Popular y el Ministro del Trabajo Dr. Clodomiro Almeyda. Estos esfuerzos se concretaron finalmente con la formación de la Central Única de Trabajadores (CUT) en febrero de 1953. ${ }^{39}$

Frente al paquete de medidas económicas, el empresariado mantuvo inicialmente una actitud de cautela. En opinión del consejero de SOFOFA y presidente de ASIMET, Eugenio Heiremans, los antecedentes económicos entregados en las cámaras del Congreso Nacional por el ministro Rosetti "confirman lo que hemos venido aseverando desde hace mucho tiempo, sin que nunca se prestara oído a nuestro llamamiento". Por su parte, Walter Müller, manifestaba que "nos hemos impuesto con gran interés de las declaraciones francas y valientes hechas por el ministro acerca de la grave situación financiera por que atraviesa el país, y lamentar que no se prestará atención a los llamados de advertencia hechos por nuestra sociedad" 40

En el marco de los primeros acercamientos entre el gobierno de Ibáñez y los empresarios, destacó la visita del ministro de Economía y Comercio, Sr. Edecio Torreblanca, al Consejo de SOFOFA el 26 de noviembre de 1952. Torreblanca miembro del partido Unión Nacional y con antiguos vínculos de amistad con Ibáñez se identificó con la línea del entendimiento con el mundo empresarial para enfrentar las dificultades económicas y la inflación. En dicho encuentro, Torreblanca expresó sus ideas personales sobre el papel de los empresarios en el terreno económico.

\footnotetext{
${ }^{37}$ El Mercurio. 4.09.1952. p. 3. Editorial: "La elección”.

${ }^{38}$ Correa. op. cit., p. 188 ,

${ }^{39}$ El Mercurio. 19.11.1952. pp. 3 y 27. Cuerpo 1 y 3. Véase, además, Moulian, Fracturas ... op. cit., p. 159 y , Ricardo Ffrench-Davis. Políticas económicas en Chile, 1952 - 1970. Centro de Estudios de Planificación Nacional. Ediciones Nueva Universidad. Universidad Católica de Chile. pp. 23 - 25.

${ }^{40}$ Industria. Boletín de la Sociedad de Fomento Fabril. N ${ }^{\text {12 }}$, Año LXIX, Diciembre, 1952. Acta de Sesiones del Consejo Directivo No 2138. 19.11.1952. p. 741.
} 
"[...] El productor necesita tranquilidad; y por eso el Gobierno tiene el propósito de mejorar todo lo posible las relaciones entre el capital y el trabajo...

Los empresarios necesitan sensación de confianza, libertad para su trabajo; debe darse alas a la iniciativa particular creadora del progreso. La exagerada intervención del Estado es funesta [...]",41

A pesar de la coincidencia de intereses entre el ministro y SOFOFA, la principal amenaza para los empresarios provino desde el Ministerio del Trabajo. En declaraciones efectuadas al matutino "El Debate", Almeyda sostuvo una opinión crítica al funcionamiento de las Juntas de Conciliación para resolver los conflictos laborales legales e ilegales. Asimismo, se manifestó favorable a la formación de una Central Única de Trabajadores ${ }^{42}$. Los gremios empresariales no dudaron en manifestar su molestia. Mediante un pronunciamiento oficial del Consejo de la SOFOFA, primero, y en audiencia con presidente de la República, después, expusieron su voz de alarma frente a las expresiones del ministro Almeyda. Para los empresarios, la intervención del gobierno en las Juntas de Conciliación en conflictos laborales, "significaría la derogación lisa y llana del Código del Trabajo, cuyo espíritu es evitar que los diferendos que surjan entre empleadores y asalariados deriven en movimientos que escapan a las normas que el mismo código". ${ }^{43}$

Para los empresarios, los conflictos laborales ilegales eran expresión de la participación de actores políticos o profesionales que alteraban y cuestionaban uno de los pilares esenciales de la empresa privada: la autoridad en la empresa.

“[...] Nuestra experiencia como empresarios confirmada por los representantes que mantenemos en la Juntas, nos indica de manera irredargüible que los conflictos ilegales provienen, en la casi totalidad de los casos, de las actuaciones de agitadores políticos o profesionales, totalmente desvinculados de las partes en conflicto, y cuyas finalidades verdaderas están muy distantes de ser las de obtener satisfacción de las necesidades efectivas del sector asalariado o una mayor justicia social [...]",4

En diciembre de 1952, el Consejo de SOFOFA expresó sus primeas críticas al plan económico de Ibáñez. Las aprehensiones se relacionaron con la propuesta sobre el crédito bancario y la creación del Banco del Estado. Una vez más, Heiremans, manifestó una opinión crítica señalando que:

"[...] un grave peligro, y es que en forma velada se ha dado a conocer el establecimiento del Banco del Estado en la exposición. Así se dice: en primer término, ordenar la política crediticia del estado mediante la centralización y unificación de todas las instituciones de crédito público a fin de fomentar y organizar un mercado de capitales que permita aprovechar racionalmente los ahorros normales del país. Sabemos que lo que se termina fomentando es el poder

\footnotetext{
${ }^{41}$ Industria. Boletín de la Sociedad de Fomento Fabril. N ${ }^{\circ}$ 12, Año LXIX, Diciembre, 1952. Acta de Sesiones del Consejo Directivo No 2139. 26.11.1952. pp. 747 - 748.

${ }^{42}$ EI Debate. 18.11.19.

${ }^{43}$ Industria. Boletín de la Sociedad de Fomento Fabril. No 12, Año LXIX, Diciembre, 1952. "La Sociedad de Fomento Fabril se dirige a S. E. El Presidente de la República observando declaraciones del señor Ministro del Trabajo”. p. 715. ${ }^{44}$ Ibid.
} 
político del Estado a través de la distribución del crédito [...]" 45

Un cuadro de incertidumbre se hizo patente con la propuesta de reforma del régimen de cambios y aumento de las atribuciones estatales en el comercio exterior. La Segunda convención Nacional de Industriales Metalúrgicos desarrollada en Talca en octubre de 1952 expresó

“[...] El Gobierno piensa establecer un cambio único que se reajustaría periódicamente. Nosotros hemos propiciado un tipo único pero libre, que se rija según la oferta y la demanda [...] Se anuncia una importación directa por parte del estado de artículos y material primas esenciales. Según informaciones posteriores dichas importaciones se harían por intermedio de la CORFO, o sea se crearía una verdadera central de compras bajo tuición estatal. Creo que la sociedad de Fomento Fabril debe oponerse rotundamente a esto [...]" 46

En el contexto descrito, no resultó extraño que reflotara el conflicto generacional al interior de SOFOFA. Los representantes de ASIMET renovaron sus demandas de un cambio en las tácticas de persuasión utilizadas por la conducción de SOFOFA. En mayo de 1953, la Asociación Metalúrgica envió una nota de protesta al Consejo de la sociedad solicitando "[...] la conveniencia de adoptar una actitud más dura hacia el Ministro de Finanzas y sus tácticas dilatorias. El Sr. Rosetti todavía no ha firmado el decreto que otorga la exención de impuestos a los bienes manufacturados exportados que él premió hace dos meses [...]"47 El decreto en cuestión proponía dejar libre de impuestos a las mercaderías exportadas directamente por sus fabricantes. Las industrias metalúrgicas eran los principales interesados en esta discusión, toda vez que se trataba del principal gremio industrial con productos elaborados para la exportación del país ${ }^{48}$

En junio del mismo año, previo a la organización de la Convención Nacional de Industria, ASIMET volvió a insistir en sus críticas. Con ocasión de la reelección de Jorge Alessandri como presidente de la CPC, Eugenio Heiremans manifestó la falta de efectividad del gremio cupular para enfrentar las dificultades de las fuerzas de la producción en el último tiempo.

“[...] calurosa adhesión y máxima colaboración al señor Alessandri, pero, no está de acuerdo en la acción pasiva que desarrolla la Confederación. Por lo que respecta a la campaña contra INACO, considera que ella no debería haberse efectuado independientemente por una rama de la producción, sino que por las cuatro en su conjunto a través de la Confederación [...] no se obtiene nada de los Poderes Públicos sin lucha y una actitud pasiva no ofrece resultados [...]" 49

\footnotetext{
45 Industria. Boletín de la Sociedad de Fomento Fabril. N ${ }^{\circ}$ 12, Año LXIX, Diciembre, 1952. Acta de Sesiones del Consejo Directivo. Op.cit. p. 751.

${ }^{46}$ Industria. Boletín de la Sociedad de Fomento Fabril. № 10, Año LXIX, octubre 1952. "Convención Nacional de Industriales Metalúricos". p. 588 y No 12, Año LXIX, Diciembre, 1952. "Sesión No 2140, 3.12.1952.

${ }^{47}$ Industria. Boletín de la Sociedad de Fomento Fabril. № 5, Año LXX, mayo, 1953. Acta de Sesiones del Consejo Directivo No 2.149. 20.05.1953

${ }^{48}$ Industria. Boletín de la Sociedad de Fomento Fabril. № 3, Año LXX, marzo, 1953. p. 244.

${ }^{49}$ Industria. Boletín de la Sociedad de Fomento Fabril. $N^{\circ} 1$, Año LXX, junio, 1953. Acta de Sesiones del Consejo Directivo $\mathrm{N}^{\circ}$ 2.150. 3.06.1953. p. 590. Véase, Cavarozzi, op. cit., pp. $252-253$.
} 
En respuesta, Alessandri destacó que la labor de la Confederación,

"[...] puede considerarse opaca, en cambio es de gran trascendencia. La situación actual de la industria y del comercio es de una gravedad enorme. La orientación política es izquierdizante, y ni en la Cámara de Diputados ni en el Senado tenemos fuerzas para enmendar leyes dictadas por el Presidente de la República. No tenemos, pues, ninguna probabilidad de obtener por vía legislativa solución a nuestras dificultades. Por otra parte, los decretos con fuerza de ley sólo se conocen una vez ya dictados. Contra esto sólo tenemos dos caminos: propiciar enmiendas por medio de la persuasión tranquila y convincente, o realizar una enérgica campaña de crítica [...] aunque desempeñe un papel menos lucido, hay mayores ventajas en la persuasión, y es preferible a la campaña enérgica que, aun cuando es más espectacular, no logra éxito y a veces su resultado es contraproducente [...]" 50

En la misma sintonía, Walter Müller, señaló:

"[...] en la próxima Convención industrial deberemos satisfacer las exigencias de los convencionales que desean una crítica espectacular, y al mismo tiempo debemos tener en cuenta que estarán presente autoridades gubernativas a las cuales conviene tratar de persuadir. Por consiguiente, es preciso que aunemos las dos modalidades, sin excedernos a ningún extremo [...]" 51

\section{La Convención Nacional de Industrias de 1953}

La convocatoria a sesión extraordinaria del Congreso Nacional por parte de Gabriel González Videla para el mes de abril de 1951, con el objetivo de discutir y aprobar un paquete amplio de reformas en temas de legislación social y laboral, ${ }^{52}$ fue el momento en que ASIMET promovió y propuso al interior de SOFOFA una serie de acciones inmediatas para enfrentar "proyectos de ley perjudiciales a la producción". Eugenio Heiremans, aprovechó la coyuntura para enviar una nota al Consejo Directivo de la Sociedad expresando:

“[...] cada uno de estos proyectos significa para la industria, y en general para la actividad comercial y producción nacional, golpes de extrema violencia [...]

[...] estos proyectos son agitados en este período pre eleccionario para beneficiar a determinados grupos políticos, y por este mismo motivo hay el temor de que sean aprobados sin mayor estudio [...]" 53

La comunicación de ASIMET solicitaba la organización de un encuentro empresarial "[...] en el cual se analizaría la gravísima situación actual del país, y que nos daría la

\footnotetext{
${ }^{50}$ Industria. Boletín de la Sociedad de Fomento Fabril. № 1, Año LXX, junio, 1953, Acta de Sesiones del Consejo Directivo No 2.150. 3.06.1953. p. 591.

${ }^{51}$ Ibíd.

${ }^{52}$ Los proyectos de ley enviados al Congreso incluyeron Reforma a las leyes de Seguro Obligatorio y de accidentes del trabajo (leyes 4054 y 4055); la inamovilidad y previsión de los empleados particulares; proyectos anti inflacionistas; modificaciones a las Caja Nacional de Ahorro, Caja de Crédito Agrario, Instituto de Crédito Industrial y Banco Central de Chile; además, de legislación para la seguridad de obreros en faenas mineras.

${ }^{53}$ Industria. Boletín de la Sociedad de Fomento Fabril. № 4. Año LXVII. Abril, 1951. p. 239.
} 
oportunidad de obtener una unión de nuestras fuerzas para seguir luchando en forma constructiva por el bien de la Patria $[\ldots]^{54}$

La propuesta de Heiremans no logró convencer al Consejo de socios de SOFOFA. En opinión de Ramón Montero, vicepresidente de la Sociedad, la materialización de la Convención debería incluir a todas las ramas de la producción $\mathrm{y}$, por consiguiente, su organización correspondía a la CPC. El consejero, Carlos Del Fierro, antes de realizar la Convención era fundamental efectuarse previamente la Junta Trimestral de socios. En definitiva, el Consejo optó por efectuar la Junta Trimestral en lugar del torneo industrial. ${ }^{55}$

En la Junta Extraordinaria de Socios de la Sociedad del 16 de mayo de 1951, Heiremans volvió a insistir en la idea de una Convención Nacional industrial. Desde su perspectiva, "[...] la Asociación de Industriales Metalúrgicos ha propuesto la celebración de una Convención de industriales y la Confederación a petición de la Sociedad está considerando si esta Convención pueda hacerse extensiva a otras ramas de la producción. Estimamos que si esta última no se puede realizar debe ser organizada por la Sociedad y los industriales [...]". 56

En esta oportunidad, la demanda de ASIMET encontró apoyo en otro miembro del consejo de la Sociedad, Alejandro Dussaillant, ${ }^{57}$ quien destaco:

"[...] el acierto y luminosidad de las notas que la Sociedad ha enviado a los poderes públicos. Pero, desgraciadamente lo políticos hacen poco de estas peticiones, porque la mayoría de los proyectos que benefician a la masa del electorado son un verdadero cohecho, mucho más grave que el dinero que se hace los días de elecciones, porque tiene consecuencias que afectan indefinidamente a todo el país. Esto no podrá decirse en notas oficiales al Gobierno, pero si puede declararse en mítines para que lo conozca la opinión pública [...]" 58

A pesar del respaldo que comenzó a concitar la propuesta de los jóvenes líderes de ASIMET entre algunos socios y consejeros de SOFOFA, al finalizar el año 1951 la conducción del principal gremio representante de toda la industria del país continuaba en manos de empresarios tradicionales como Müller, Montero, Katz y Alessandri. Los meses de junio y julio del año 1951, mostraron el peso de la influencia que aún mantenían Müller

\footnotetext{
54 Ibíd.

${ }^{55}$ Industria. Boletín de la Sociedad de Fomento Fabril. № 5. Año LXVII. Mayo, 1951. p. 294.

${ }^{56}$ Industria. Boletín de la Sociedad de Fomento Fabril. N ${ }^{\circ}$ 5. Año LXVII. Mayo, 1951. Acta Junta General extraordinaria de Socios del 16 d emayo de 1951. p. 307.

${ }^{57}$ Alejandro Dussaillant (1880 - 1973) Dueño de la Viña Casablanca de Lontué, una de las más modernas en la primera mitad del siglo XX y destinada al consumo nacional e internacional. Director de la Sociedad Anónima Sub-Productos Vinícolas Lontué. Fue elegido diputado por la Duodécima Circunscripción Departamental "Talca, Lontué y Curepto", período 1930 a 1934; fue diputado reemplazante en la Comisión Permanente de Hacienda e integró la Comisión Permanente de Industria y Comercio. Reelecto diputado por la misma Circunscripción, pero que ahora sólo incluía a Lontué y Talca, periodo 1933 a 1937; integró la Comisión Permanente de Hacienda, de la que fue presidente; y la Comisión Permanente de Industrias. Elegido nuevamente diputado, por la reformada Duodécima Agrupación Departamental "Lontué, Talca y Curepto", período 1937 a 1941; integró la Comisión Permanente de Hacienda. Miembro de la Sociedad Nacional de Agricultura, SNA, de la Sociedad de Fomento Fabril, SOFOFA, del Club de La Unión y del Club Liberal. http://historiapolitica.bcn.cl/resenas parlamentarias/wiki/Alejandro Dussaillant Louandre.

${ }^{58}$ Industria. Boletín de la Sociedad de Fomento Fabril. № 5. Año LXVII. Mayo, 1951. Acta Junta General extraordinaria de Socios del 16 d emayo de 1951. p. 308.
} 
y Alessandri, quienes se transformaron en las figuras gremiales que hicieron frente a los proyectos de estabilización y reformas en temas de legislación social y laboral que propuso la administración de González Videla. ${ }^{59}$

Con todo, la campaña electoral para las presidenciales de 1952 interrumpió el debate y controversias dentro de las filas de SOFOFA y, específicamente, la realización de una gran convención de industriales. El creciente cuestionamiento de los jóvenes líderes reformista de SOFOFA a la conducción de los industriales más tradicionales bajo el liderazgo de Müller y Alessandri quedaría suspendido en interés de una preocupación común: intentar hacer de Arturo Matte Larraín el nuevo presidente de la República.

En sesión del Consejo de Directorio de SOFOFA de 25 marzo de 1953, Eugenio Heiremans reiteró la idea de realizar una contundente convención de industriales para el mes de junio del mismo año. Los motivos que esgrimió se enmarcaron en dificultades de cooperación entre los socios y la necesidad de aunar voluntades frente a los desafíos políticos actuales.

"[...] la poca cooperación que los industriales prestan a la labor de la Sociedad, lo que se demuestra en la escasa asistencia a las juntas de socios. (Agregó que) antes que se produzca una disminución de la influencia de la Sociedad ante los poderes públicos por esta apatía de los industriales, es urgente realizar un trabajo de agrupación de las fuerzas gremiales y de actualización de la labor de la Sociedad $[\ldots] " 60$

La iniciativa, además, se instalaba cuando Domingo Arteaga Infante y Eugenio Heiremans comenzaron paulatinamente a controlar la mesa directiva de SOFOFA y se posicionaron como los articuladores principales de la Comisión organizadora del encuentro empresarial. La convención industrial surgió en momentos en que la etapa populista del gobierno de Ibáñez había afectado seriamente las influencias empresariales en el gobierno y, específicamente, cuando un conjunto de iniciativas del ejecutivo se volvieron una seria amenaza para el mundo de la producción. En opinión de Ernesto Ayala Oliva,

"[...] El futuro inmediato de la industria en Chile no se ve claro. Hay para ella confusionismo y trabas y vientos de fronda. Se ha hablado, cometiendo gravísimo error, a nuestro juicio, de nacionalizar las minas del carbón y otras industrias importantes. Los conflictos de trabajo han mantenido su base política y la inflación está sentando sus garras cada vez más profundas en el corazón de Chile [...]" 61

El Mercurio, quien realizó una amplia campaña de difusión del encuentro empresarial, destacó la situación de incertidumbre y amenaza de los empresarios industriales frente a las políticas gubernamentales. "[...] las erróneas orientaciones intervencionistas que en los últimos años han alcanzado caracteres amenazantes para la capitalización y estabilidad de

\footnotetext{
${ }^{59}$ Industria. Boletín de la Sociedad de Fomento Fabril. No 7. Año LXVII. Julio, 1951. Véase la "Asamblea Nacional de la Producción y del Comercio contra proyectos económicos lesivos a los intereses generales del país". 9.07.1951, Teatro Victoria de Santiago. pp. $397-408$.

${ }^{60}$ Industria. Boletín de la Sociedad de Fomento Fabril. № 1, Año LXIX, enero, 1953. Acta de Sesiones del Consejo Directivo $N^{\circ} 2.145,25.03 .1953$. p. 69. Las actas de sesiones del Consejo Directivo correspondientes al 11 y 25 de marzo de 1953 fueron insertadas por retardo en imprimir la revista del mes de enero del mismo año.

${ }^{61}$ Ibid.
} 
los negocios $[\ldots] ”, 62$

Efectivamente, la coyuntura que se abría en marzo de 1953 para las asociaciones empresariales fue de incertidumbre y amenaza. En este análisis tuvieron en cuenta los resultados electorales de las elecciones parlamentarias del $1^{\circ}$ de marzo de 1953. En efecto, surgió una nueva configuración del sistema de partidos, cuyo carácter fundamental fue la fragmentación del escenario político en comparación con las elecciones de 1949. El principal cambio que se verificó fue el debilitamiento de los denominados partidos históricos: radicales, conservadores y liberales. Estas tres fuerzas disminuyeron su votación desde el $60 \%$ de votos en 1949 al 33\% de electores en 1953. Sin lugar a dudas, la derecha política fue el sector político que mostró una ostensible baja en su performance electoral. Diferente fue el comportamiento electoral para los dos partidos más importantes del ibañismo. El Agrario Laborista obtuvo el 19,73\% de las preferencias y el Partido Socialista Popular alcanzó el $7 \%$ de los votos. ${ }^{63}$

Una segunda amenaza provino del ministro Clodomiro Almeyda. Bajo su gestión dio su apoyo a los dirigentes sindicales que intentaban crear la Central Única de Trabajadores, arbitró favorablemente en conflictos laborales y promovió el salario mínimo para los obreros agrícolas. En editorial de El Mercurio del 5 de marzo de 1953, se puso de manifiesto la actitud de Almeyda en los conflictos laborales,

"[...] la actuación que ha desarrollado el actual ministro del Trabajo se caracteriza por un criterio enteramente ajeno a la función arbitral que le corresponde al Gobierno en los conflictos entre las empresas y obreros, y por el propósito definido de anticipar soluciones favorables a la parte trabajadora sin considerar la repercusión que ellas tengan para la estabilidad de la producción para la economía nacional $[\ldots] " 64$

La conformación de la Central Única de Trabajadores y el aumento de movilizaciones laborales consideradas por el empresariado como "ilegales" contaron con la aprobación del gobierno. SOFOFA levantó su voz de alarma frente a conflictos laborales. Durante el conflicto laboral que afectaban los establecimientos industriales de propiedad del consejero de la Sociedad Domingo Arteaga Infante, SOFOFA, dirigió una nota al ministro del Interior manifestando que "no puede permanecer indiferente ante los numerosos conflictos colectivos de trabajo que continúan suscitándose y las huelgas legales o ilegales que con este motivo han sobrevenido con perjuicios evidentes para la marcha de las industrias y para la economía del país". ${ }^{65}$

Finalmente, dos iniciativas de gobierno se transformaron en determinantes para el mundo empresarial: El Convenio entre Chile y Argentina suscrito el 21 de febrero de 1953 por los

\footnotetext{
${ }^{62}$ El Mercurio. 20.06.1953. p. 3. Cuerpo 1. Editorial: Convención Nacional de la Industria

${ }^{63}$ Véase, Germán Urzúa Valenzuela. Historia política de Chile y su evolución electoral desde 1810 a 1992. Editorial Jurídica de Chile. Santiago, 1992. pp. 564 - 565; Federico G. Gil. El sistema político de Chile. Editorial Andrés Bello. Santiago de Chile 1969. pp. 250 - 251. Moulian, Fracturas ... op. cit., p. 160.

${ }^{64}$ El Mercurio. 5.03.1953. p. 3. Editorial: "Errónea política del trabajo"

${ }^{65}$ El Mercurio. 20.03.1953. p. 28 (Cuerpo 3). "Inserción: La Sociedad de Fomento Fabril protesta por violaciones legales amparadas por el Intendente".
} 
presidentes Carlos Ibáñez del Campo y Juan Domingo Perón, y la creación del Instituto Nacional de Comercio (INACO).

La denominada "Acta de Santiago" expresó los planes de integración económica binacional bajo los principios comunes de soberanía política, justicia social e independencia económica. ${ }^{66}$ Las principales advertencias sobre los perjuicios del acuerdo de "Cordillera Libre y Unión Aduanera" provino de la Acción Nacional Agraria. En su opinión, "la complementación económica de que ahora se habla y que algunos conciben también como política, representaría, en los términos en que hasta este momento se ha planteado, la anemia industrial y agrícola de Chile". ${ }^{67}$ Por su parte, el boletín de industria de SOFOFA, manifestaba que "la amplitud de esta fórmula ha causado verdadera alarma entre los productores de Chile y, sin duda, ellos son perfectamente justificado, ya que la aplicación de un tratado de esta naturaleza significaría la abolición de todas las medidas dictadas a través de la historia económica del país". 68

En comunicación escrita al departamento de Política Comercial del Ministerio de Relaciones exteriores, SOFOFA presentó sus observaciones al Acta de Santiago:

“[...] Concordamos, pues, con el propósito de mejorar nuestras relaciones comerciales con la nación limítrofe, nos permitimos sugerir que ello se haga mediante un estudio en detalle de los artículos a intercambiarse y no por medio de una abolición general de derechos que significaría en la práctica paralizar un considerable número de actividades productoras nacionales que llevan una vida precaria debido al proceso inflacionista, a la onerosa legislación social y a los elevados impuestos vigentes en nuestro país, factores todos estos que no inciden en modo tan grave como entre nosotros sobre la producción argentina [...]" 69

En cuanto al INACO, las organizaciones gremiales levantaron su preocupación por considerar la institución parte de una medida intervencionista estatal. En declaración pública la Cámara Central de Comercio de Chile consideró a INACO como un monopolio estatal que estaría "sujeto a las influencias políticas y al lento e inepto rodaje burocrático (que) sería incapaz de reemplazar los eficaces servicios del comercio privado". ${ }^{70}$

En opinión de Hernán Elgueta Guerin, la creación de INACO representaba:

"[...] (un) competidor de la actividad privada. No se puede pensar que existan hombres de negocio que consideren prudente competir con un organismo del Estado que no pagará impuestos, que no pagará intereses al capital, que podrá obtener reducción de derechos aduaneros, que no sufrirá tramitaciones para obtener

\footnotetext{
${ }^{66}$ Véase a Rodrigo Mardonez Zuñiga. “Chile y su comercio con Argentina, 1930 - 1960”. Revista Historia. Volúmen 29, 1995 - 1996. Instituto de Historia. Pontificaia Universidad Católica de Chile. p. 251; Arturo Olavarria Bravo, op. cit., p. 187.

${ }^{67}$ Industria. Boletín de la Sociedad de Fomento Fabril. № 3, Año LXX, marzo, 1953. p. 219. "La agricultura chilena frente a los proyectos de cordillera libre y unión aduanera".

${ }^{68}$ Industria. Boletín de la Sociedad de Fomento Fabril. No 3, Año LXX, marzo, 1953. p. 205. Editorial: "Proyecto de Tratado con la Argentina".

${ }^{69}$ Industria. Boletín de la Sociedad de Fomento Fabril. N ${ }^{\circ}$ 3, Año LXX, marzo, 1953. p. 209. "Puntos de vista de fomento fabril frente al tratado con Argentina".

${ }^{70}$ El Mercurio. 18.05.1953. Cuerpo 2. p. 13. "Instituto de Comercio significa establecer monopolio a favor del Estado"
} 
sus permisos de importación y que, por último, tendrá el privilegio, inalcanzable para el sector privado, de poder vender bajo el costo y perder dinero cuando lo estime necesario; pues dichas perdidas se vaciarán, en forma imperceptible para la mayoría del país, en el océano del presupuesto fiscal [...]" 71

En rigor, INACO constituyó para el mundo empresarial una clara amenaza populista y estatista. Mediante la creación de este organismo, el gobierno se propuso acrecentar sustancialmente las atribuciones del estatales en el comercio exterior, controlando e intentando desplazar al sector comercial privado.

Con todo, los días 19, 20 y 21 de junio del año 1953, en Viña del Mar, tuvo lugar la Convención Nacional de Industria. El torneo industrial marcó un punto de inflexión en las futuras relaciones entre SOFOFA y los poderes políticos. Con la presencia de casi mil delegados de todo el país, quienes representaron a 7.500 empresas y talleres de todo el país, el evento mostró un camino de renovación y re-articulación de la clase empresarial. ${ }^{72}$

La comisión organizadora del encuentro estuvo integrada por Walter Müller, presidente de SOFOFA; Guillermo Guzmán Durán, vicepresidente de la comisión organizadora; Benjamín Aguirre; José Caffarena, Luis Bengoa, Domingo Arteaga y el presidente de la comisión Eugenio Heiremans. La mesa directiva de la convención quedó conformada por Walter Müller, representante de SOFOFA, Guillermo Guzmán Durán en representación de las fuerzas productoras de Valparaíso, Gregorio Díaz como representante de la zona sur y convencional de la Fábrica de Loza de Penco y Enrique Quintano, presidente del comité de industria de Antofagasta y representante de los industriales de la zona norte. Guillermo Guzmán Durán, un año más tarde, se convertiría en presidente fundador de la Asociación de Industriales de Valparaíso y Aconcagua (ASIVA). ${ }^{73}$ Por último, figuró entre los invitados de honor del encuentro empresarial el periodista Joaquín Lepeley, en calidad de Director de El Mercurio. ${ }^{74}$

El programa, temario y resoluciones del encuentro significaron un duro revés para las políticas económicas y sociales aplicadas por el ibañismo en su fase populista. Los convencionales discutieron en el trabajo de las seis comisiones el intervencionismo estatal, el aumento constante de los gastos del servicio público, el incremento de la inflación, la intervención estatal en la fijación de precios, las relaciones entre capital y trabajo, el régimen monetario y la política de cambios internacionales. ${ }^{75}$ Walter Müller, presentó un discurso de apertura crítico al gobierno de Ibáñez,

“[...] Dado el enorme aporte de la industria a la vida económica de la nación se puede afirmar sin necesidad de mayores pruebas que todo tropiezo que se oponga al desarrollo de esta actividad se traduce en un perjuicio de orden nacional [...]

Es deplorable constatar; sin embargo, que a pesar de la importancia de la industria y de la experiencia de sus organizaciones y personeros, ellas no han sido tomadas

\footnotetext{
71 Ibid,

${ }^{72}$ El Mercurio. 19.06.1953. p. 23. LIV. No 19.045

${ }^{73}$ EI Mercurio de Valparaíso. 17.08.2014. "60 año de ASIVA. 1954 - 2004"

${ }^{74}$ Industria. Boletín Sociedad de Fomento Fabril. № 6, Año LXX, junio 1953. p. 514.

${ }^{75}$ El Mercurio. 18.06.1953. p. 3. "Problemas de nuestra organización industrial".
} 
debidamente en cuenta en la formulación de los programas de Gobierno, y no han podido pesar suficientemente ante los poderes constituidos y la opinión pública del país en general $[\ldots] " 76$

Por su parte, Pedro Ibáñez, presidente de la Cámara de Comercio de Chile y relator de la comisión "Enseñanza técnica y profesional" manifestó:

“[...] Desde luego, salta a la vista que, en la conducta de la política económica nacional, se ha establecido desde hace mucho tiempo una lucha entre quienes desean solucionar nuestras angustias mediante estudios serios y acciones eficaces y quienes, guiados por su desconocimiento de estas materias, dan satisfacción a demandas demagógicas, agravan los peligros que nos rodean y empujan al país a un colapso inevitable, si se persiste en tan equivocados rumbos. Frente a estas confusas y sombrías circunstancias, no cabe duda que la voluntad de este gran sector de nuestra patria que representa las fuerzas de la producción, respaldará políticamente a los gobernantes conscientes de su responsabilidad, que aspiran a implementar un régimen austero, ponderado y realizador, y a terminar con la demagogia de eso otro gran sector que paraliza y anula la propia acción del gobierno [...]"77

Ciertamente, el encuentro empresarial posibilitó a las asociaciones gremiales avanzar desde la intervención pública en términos de "las políticas" sectoriales hacia la "vida política". En función de lo anterior, a través de la convención industrial las organizaciones gremiales desplegaron una estrategia ofensiva - defensiva que utilizando un discurso técnico se propuso transmitir ideas $\mathrm{y}$, de paso, posicionar un diálogo más confrontacional con las autoridades sectoriales del Gobierno y los parlamentarios. Como sostuvo Eugenio Heiremans,

“[...] En el origen de esta Convención hay conceptos fundamentales que no podríamos pasar por alto en esta oportunidad. Es necesario que se comprenda de una vez por todas que el creador de riquezas, el que transforma lo que entrega la naturaleza para proporcionar bienes útiles a la colectividad, es un hombre digno de estímulo y todo respeto. El progreso, a través de la historia, sólo ha sido posible en base al esfuerzo tenaz de estos hombres; sin embargo, y triste es reconocerlo, en nuestro país se les ha postergado en forma injusta, desconociendo la importancia que para la colectividad reviste su labor [...]". ${ }^{78}$

Efectivamente, la unidad de los empresarios era fundamental para el éxito de la convención industrial y, específicamente, para enfrentar la amenaza populista ibañista. En este sentido, Heiremans manifestó que:

“[...] Como miembros de una colectividad, y por la responsabilidad que tenemos como administradores de capitales y directores de trabajadores, tenemos obligación

\footnotetext{
${ }^{76}$ Discurso de Walter Müller en el banquete de clausura de la Convención Nacional de Industria: "La industria manufacturera es la rama más importante de la vida económica nacional". Industria. Boletín Sociedad de Fomento Fabril. $\mathrm{N}^{\circ}$ 6, Año LXX, junio 1953. p. 535.

77 El Mercurio. 21.06.1953. p. 27. Cuerpo 3: "Con asistencia del Presidente de la República será clausurada hoy Convención Nacional de Industrial”

${ }^{78}$ Industria. Boletín Sociedad de Fomento Fabril. No 6, Año LXX, junio 1953. Eugenio Heiremans. "De nuestro esfuerzo dependen en gran parte destinos del progreso nacional”. p. 527.
} 
ineludible de ser parte activa y dinámica de la vida nacional. Aceptemos, pues, como primera medida para el éxito de nuestra causa, esta gran falla que hemos tenido, y hagámonos el firme propósito de realizar los mayores esfuerzos para variar fundamentalmente nuestra forma de actuar [...]

Nuestra primera etapa está encaminada a obtener la unión férrea de los industriales del país para que formando un frente común podamos superar la mera actuación defensiva para lanzarnos en pos de un plan constructivo [...]" 79

En tono similar, el empresario textil, Sr. Juan Yarur, formuló a El Mercurio las siguientes declaraciones días antes de la realización de la convención,

"[...] Generalmente se enfrentaba la solución de los problemas que afectan a la industria en forma aislada y sólo después que estos entraban a una etapa de crisis.

[...] de la Convención Nacional de industria pueden surgir las bases fundamentales de una industrialización racionalizada, propuesta por los propios interesados, lo cual evitará la anarquía y la secuela de la frecuente estatización de algunas iniciativas creadoras que no encuentran perspectivas de desarrollo, por estar desvinculadas de la realidad económico-industrial del país [...]" 80

En la ceremonia de clausura del torneo industrial, Jorge Alessandri, compartió la crítica del aumento de las atribuciones del Estado en el comercio interno y exterior. En presencia de Carlos Ibáñez del Campo y su Ministro de Economía, Rafael Tarud, sostuvo que "se exagera constantemente la intervención estatal en la economía olvidando casi siempre que esta no es por sí misma una meta, sino que un medio cuya finalidad es defender los intereses colectivos". ${ }^{81}$ Asimismo, aprovechó la oportunidad para analizar el desenvolvimiento económico chileno desde 1938 y manifestar que el programa político y económico del ibañismo estaba destinado a zozobrar debido a las medidas de intervencionismo estatal:

"[...] Su implantación indiscriminada, como ha ocurrido corrientemente, conduce a resultados diametralmente opuestos y la transforman en una nueva y de las más connotadas causas del proceso inflacionista al frenar la producción, al eliminar todo aliciente para el abaratamiento de los costos y al dificultar el normal aprovisionamiento y la distribución; factores que conducen por si mismos a encarecer los productos y a toda clase de abusos y de especulaciones. Esta forma de practicarla tiene, también, otro aspecto no menos grave y peligroso y es las posibilidades inmensas que más tarde o más temprano, abre a la gestión administrativa y, luego, a la desmoralización de la vida política y económica" 82

El evento industrial acordó las siguientes medidas:

a) Coordinación con entidades gremiales, tanto de obreros como de empleados, para enfrentar los problemas económicos y políticos comunes.

\footnotetext{
${ }^{79}$ Ibid., p. 258 - 259.

${ }^{80}$ El Mercurio. 6.06.1953. Cuerpo 2.

${ }^{81}$ Industria. Boletín Sociedad de Fomento Fabril. № 6, Año LXX, junio 1953. Jorge Alessandri Rodríguez. Discurso Banquete de Clausura Convención Nacional de Industria. p. 545.

${ }^{82}$ Ibid.
} 
b) Organización de un organismo técnico en SOFOFA para el estudio de los problemas económicos que afecten la producción en base de antecedentes estadísticos para informar al país en general, y en especial, a las entidades de la producción.

c) Constituir comisiones zonales o nacionales para orientar a los representantes patronales y los obreros.

d) Que el Estado intervenga en aquellos casos en que el capital privado no pueda hacerlo por la naturaleza de la inversión.

e) Incorporar a las entidades de la producción en la Comisión que estudiaba las reformas al Código del Trabajo.

f) Considerar el carácter técnico de los cargos de ministro del Trabajo, Director General del Trabajo, presidentes de las Juntas de Conciliación e Inspectores provinciales".

g) Diferenciar entre huelgas legales e ilegales y respetar el Código del Trabajo. ${ }^{83}$

El aumento de las huelgas legales e ilegales, fue uno de los temas centrales de debate en la convención industrial. Al respecto, se ha sostenido que las fuerzas de la producción mantuvieron una conducta de aceptación formal de las relaciones laborales establecidas en las leyes sociales de los años $20 \mathrm{y}$, específicamente, del Código del Trabajo de $1931 .{ }^{84} \mathrm{Sin}$ embargo, la aceptación formal de las organizaciones obreras y sus demandas salariales tuvieron como paraguas la aplicación de Ley 8.987 (Ley de Defensa Permanente de la Democracia). Mediante esta legislación no sólo se persiguió la presencia pública del Partido Comunista y sus sindicatos afines; sino que también se afectó el derecho a huelga y las manifestaciones obreras. Lo anterior posibilitó que entre 1944 y 1951 se produjeran una situación de creciente recesión de las manifestaciones conflictivas legales y un aumento sostenido de las huelgas ilegales. ${ }^{85}$

En el discurso de clausura de la Convención, Walter Müller, colocó el acento en la sobrecarga de la demanda económica de sindicatos y trabajadores.

"Las relaciones entre capital y trabajo constituyen nuestra preocupación permanente. Ellas han sido sistemáticamente deformadas por intervenciones demagógicas o políticas, prometiendo falacias imposibles de cumplir [...]

Los industriales y productores [...] no demuestran insensibilidad social, sino que espíritu realista al oponerse a todas las demasías que, olvidando dicha realidad, pretenden resolver los problemas nacionales por encima de ella creando inflación y todo cortejo de descontento social y de inestabilidad económica" 86

En consecuencia, la raíz de los problemas entre capital y trabajo y de los factores inflacionarios se encontraban en "gastos fiscales desorbitados; aumento de jornales y

\footnotetext{
${ }^{83}$ El Mercurio. 22.06.1953. pp. 30 - 31. Cuerpo 3: "Conclusiones de la Convención de Industrias"

84 Joaquín Fernández Abara y Margarita Goldflam Leiva. "Hacia la constitución de una economía de mercados jerárquicos: modernización capitalista y tradicionalismo social en los industriales chilenos (1952 - 1958)”. Les Cahiers ALHIM. Partis, mouvements et organisations patronales: les droites dans le Cone Sud Latino- américain (1950 - 2016). $\mathrm{N}^{\circ} 32,2016$.

${ }^{85}$ Crisóstomo Pizarro. La Huelga Obrera en Chile. Ediciones SUR. Santiago de Chile, 1996. p. 137 - 139.

${ }^{86}$ Industria. Boletín Sociedad de Fomento Fabril. № 6, Año LXX, junio 1953. p. 537
} 
sueldos en mucho mayor proporción que el aumento del costo de la vida". ${ }^{87}$ La presencia de sectores políticos proclives a satisfacer las demandas salariales y no enfrentar la inflación se transformó en un marco de incertidumbres y amenazas a los intereses de los empresarios. En palabras de Jorge Alessandri,

“[...] Se atiende al estado de ánimo, que parece prevalecer en vastos sectores asalariados y que encuentra acogida en importantes conglomerados políticos en orden a reclamar para aquellas ventajas aún mayores que las ya alcanzadas y que [...] junto con la notoria descapitalización de las empresas públicas y privadas son la consecuencia precisa de que aquellas ya han sobrepasado lo que realmente permitía hacer el incremento efectivo de la producción [...]"\$88

Por otra parte, los industriales aprovecharon la convención industrial para cuestionar el desempeño del ministro de Economía Rafael Tarud. En la perspectiva de los hombres de empresa, su gestión incrementó las atribuciones estatales en el comercio exterior y eliminó a los representantes de la producción del Consejo de Comercio Exterior, con lo cual quebraba el entendimiento entre capital privado y Estado. ${ }^{89}$ Consiente de estas críticas, Tarud aprovechó la cena de clausura del torneo industrial para, en nombre del gobierno, profundizar sobre lo que él denominó como "derecha Económica".

"[...] Los hombres de esfuerzo, sean grandes o pequeños, jamás se han identificado con la llamada "Derecha Económica" [...] quienes forman parte de este sector privilegiado los que han satisfecho sus ansias de lucro y que han acumulado un gran potencial económico y suelen ser arrastrados - para mantener ese predominio - a invadir el campo de la política. Estos y no otros constituyen la Derecha Económica.

Y esta Derecha Económica, señores, lejos de ser un factor de progreso es un grave peligro para la estabilidad del país. Usar el poder político, no en razón de altos ideales, sino de intereses de círculos, es trastocar la jerarquía de valores, es empequeñecer una función elevada, es, en fin, desvirtuar los afanes más nobles que inspiran al hombre: El servicio de su Patria [...]" 90

Un hecho relevante y con efectos de mediano y largo alcance fueron la discusión y resoluciones de dos mesas de trabajo fundamentales para los gremios empresariales: la organización de las fuerzas de la producción y la asistencia técnica. El objetivo, en ambas mesas fue incorporar modernos métodos de organización, funcionamiento y producción. Para tales efectos, se mandató el refuerzo de las actuales asociaciones gremiales industriales y la formación de nuevos gremios en todos los sectores y regiones del país. Con este objetivo, los consejeros de SOFOFA conformaron en el mes de junio de 1953 una Comisión integrada por Jorge Alessandri, Eugenio Heiremans, Domingo Arteaga, Ernesto Ayala, José Caffarena, Manuel Comandari, Benjamín Hurtado, José Merino, Rodolfo

\footnotetext{
${ }^{87}$ Ibíd. p. 501.

${ }^{88}$ Ibíd.

${ }^{89}$ Correa, op. cit., pp. $193-194$.

${ }^{90}$ El Mercurio. 24.06.1953. p. 3. Cuerpo 1: "Real sentido de la función capitalista". Véase también en Industria. Boletín Sociedad de Fomento Fabril. N 6, Año LXX, junio 1953. Rafael Tarud, Ministro de Economía y Comercio, Rafael Tarud. Discurso en nombre del Gobierno en "Banquete de Clausura Convención Nacional de Industria”. p. 553.
} 
Opazo y Jorge Yarur. ${ }^{91}$ Entre las primeras medidas que "Comisión de Reorganización de las Fuerzas de la Producción” (como se denominó) propusieron al Consejo reformas a los estatutos de SOFOFA, multas por inasistencia a las sesiones del consejo directivo y la realización de "visitas a provincias para reorganizar asociaciones industriales (y) campañas de socios". 92

Tan relevante como lo anterior fue el acuerdo adoptado en la Convención de recomendar a los industriales del país relacionarse con el "Servicio de Cooperación Técnica Industrial" (en adelante "El Servicio"). ${ }^{93}$ El Servicio formó parte de un convenio suscrito en junio de 1952 entre CORFO y el International Cooperation Administration (ICA), dependiente del Gobierno de Estados Unidos. Un año más tarde, el convenio entraba en plena vigencia y funcionamiento.

El acuerdo de cooperación tuvo como representante en Chile a un funcionario clave: Albion Patterson. Su figura ha sido destacada por Manuel Gárate en profundidad, considerándolo uno de los "padres de los Chicago Boys" en Chile junto a Theodore W. Schultz y Julio Chaná94. Patterson cumplió un papel de enlace en las negociaciones entre la Facultad de Ciencias Económicas de la Pontificia Universidad Católica de Chile y el Departamento de Economía de la Universidad de Chicago para el establecimiento de un acuerdo de cooperación académica para la formación de economistas chilenos que pudieran contrarrestar la influencia del estructuralismo y el marxismo en la formación profesional de los economistas chilenos. ${ }^{95}$

La relevancia de la labor que desarrolló Mr. Patterson durante los cuatro años de permanencia en el país fueron reconocidas por los sectores de la producción y del comercio en la cena de homenaje realizada en septiembre de 1957. Distinguido en como socio honorario de SOFOFA, el ingeniero Raúl Sáez ${ }^{96}$ destacó cuatro iniciativas de colaboración

\footnotetext{
${ }^{91}$ Sesión de Consejeros de SOFOFA N ${ }^{\circ}$ 2.151, 24.06.1953. En Industria. Boletín Sociedad de Fomento Fabril. Nº 6, Op. Cit. p. 598.

${ }^{92}$ Sesión de Consejeros de SOFOFA N $2.153,22.07 .1953$. En Industria. Boletín Sociedad de Fomento Fabril. No 7 , Año LXX, julio 1953. pp. 673.

${ }^{93}$ El Mercurio. 22.06.1953. pp. $30-31$.

94 Julio Chaná Cariola (1909 - 1995) Decano de la Facultad de Ciencias Económicas y Sociales de la Universidad Católica entre 1954 - 1964. Theodore W. Schultz, Decano de la facultad de Economía de la Universidad de Chicago entre $1946-1959$.

${ }^{95}$ Gárate, op. cit., pp. 122 - 124.

${ }^{96}$ Raúl Sáez (1913 - 1992). Ingeniero Civil de la Universidad de Chile y Premio Nacional de Ciencias Aplicadas y Tecnológicas en 1992. Su primer proyecto fue el Plan de Electrificación Nacional, el cual desencadenó la fundación de ENDESA donde asumió la gerencia hasta 1961. Asimismo, se desempeñó como ingeniero jefe de la Compañía de Acero del Pacífico (CAP) y le correspondió estudiar soluciones técnicas para la construcción de la usina de la siderúrgica Huachipato. Entre 1950 y 1952, organizó y fue el primer jefe del Departamento de Planificación Nacional de CORFO. Dirigió los estudios técnicos, económicos y financieros que permitieron organizar la Industria Azucarera de BetarragaSacarina que condujeron, en 1952, a la creación de la Industria Azucarera Nacional S.A (IANSA). Fue, además, el primer presidente de la Empresa Nacional de Telecomunicaciones (ENTEL). Dirigió los trabajos para evitar que el lago Riñihue inundara con sus aguas la ciudad de Valdivia, a raíz del terremoto que afectó la zona sur del país el año 1960 .
}

Nombrado Ministro de Hacienda en 1968, cargo que abandonó a las pocas semanas, dirigió las negociaciones que condujeron a la Chilenización del cobre y concibió la estrategia que debía inspirar la Corporación Nacional del Cobre de Chile (CODELCO - Chile). En septiembre de 1973 fue llamado al Gobierno por el general Gustavo Leigh, participando 
dirigidas por Patterson y que, en su juicio, habían transformado a Chile en "[...] una especie de laboratorio continental en el cual se forjan exitosos experimentos que comienzan a ser adoptados en los programas de la Administración de Cooperación Internacional en otros países latinoamericanos [...]". ${ }^{97}$ Los programas a los que hacía alusión fueron "El Plan Chillán"; el "Instituto Chileno de Administración Racional de Empresas" (ICARE); la operación "jefe" y la ejecución del "Agro Servicio" cuyo propósito fue la instalación de un programa de asistencia técnica y extensión agrícola.

Fruto de las experiencias de colaboración de la misión de Patterson y la ICA en Chile, importantes sectores de los gremios empresariales fortalecieron la desconfianza en el Estado y los partidos políticos en la intromisión no racional en la economía. En este proceso, la influencia ideológica norteamericana y su modelo histórico de industrialización fueron claves. La trascendencia de ICA y, específicamente, la labor de Mr. Patterson fue central en los cambios que comenzaron a desplegarse en SOFOFA durante la década de 1950. Su labor de cooperación con los gremios empresariales coincidió con un movimiento de renovación de sus cuadros dirigentes; entre los que destacaron Domingo Arteaga Infante, Eugenio Heiremans, Ernesto Ayala, Hernán Briones, Juan Yarur Banna, entre otros. Este segmento del empresariado se propuso imponer, desde SOFOFA, un programa de rearticulación orgánico gremial funcional a la formulación en el mediano plazo de un proyecto económico y político desvinculado de los partidos políticos tradicionales de la derecha.

\section{Reflexiones Finales}

El análisis del conflicto generacional al interior de SOFOFA, de las transformaciones del discurso y programa de los industriales chilenos durante la fase populista del segundo gobierno de Carlos Ibáñez mostró en toda su dimensión el comportamiento político de los gremios empresariales cuando enfrentan contextos de incertidumbre, malestar o amenaza. Este contexto, las conclusiones y debates de la convención industrial posibilitaron que los hombres de empresa no sólo expresarán su opinión sobre las dificultades sectoriales vinculadas a la industria, sino que también respecto de las políticas económicas y sociales de la fase populista del gobierno ibañista. En rigor, ninguna de las demandas y alertas empresariales fue nueva. Lo que se modificó sustancialmente en esta oportunidad fue el contexto en que fueron expresadas las críticas. En efecto, fue la primera vez desde 1944 que los industriales, reunidos en una convención, expresaban públicamente sus reivindicaciones y temores frente la gestión gubernamental. ${ }^{98}$.

Asimismo, esta fase constituyó la primera reacción crítica del conjunto de las fuerzas industriales y de SOFOFA, en particular, no sólo contra las medidas económicas del gobierno de Ibáñez, sino que contra un capitalismo supervisado por el Estado. Una

como asesor económico de la Junta Militar, especialmente, en materias relacionadas con la Coordinación Económica y Desarrollo hasta 1975. Véase, Raúl Sáez. Hombre del siglo XX. Editorial Dolmen. 2 tomos. Santiago de Chile, 1994.

${ }^{97}$ Industria. Boletín Sociedad de Fomento Fabril. № 9. Septiembre, 1957. p. 18.

${ }^{98}$ Convención Industrial de Chile, celebrada entre el 15 al 17 de diciembre de 1944 en la ciudad de Santiago. 
arremetida sobre las bases del Estado de Compromiso surgido en la década de los 30'. Parafraseando a Claus Offe, para un segmento del mundo empresarial "el Estado fue considerado la enfermedad de aquello que pretendía curar". ${ }^{99}$ Dicho de otro modo, para los gremios industriales este acuerdo político en lugar de armonizar los conflictos de una sociedad mercantil, los exacerbó. Su rol de estabilizador interno de tipo económico, social y político terminó limitando que las fuerzas del mercado funcionen de modo apropiado y benéfico.

Finalmente, es necesario matizar que hacia junio de 1953 se encontrará resuelto un conflicto generacional al interior del gremio industrial. En otras palabras, la contraposición entre un sector juvenil partidario de una política más agresiva contra las circunstancias económicas y políticas del país (los empresarios duros) y otro sector (empresarios blandos) gremial proclive a la continuidad en el lobby y los métodos corporativistas de colaboración con el Estado. ${ }^{100}$ Ciertamente, la Convención Nacional de Industrias evidenció contradicciones, críticas y diferencias sobre el tipo de relaciones futuras entre el empresariado y el poder político. Estas reacciones empresariales comenzaron a quedar de manifiesto frente al cuadro de incertidumbre y amenaza del intervencionismo estatal propiciado por el ibañismo. No obstante, la Convención Nacional de Industrias evidenció que por sobre las diferencias entre duros y blandos, aún existían motivos que unían a ambas sensibilidades: la fase populista del gobierno de Ibáñez.

La acentuación de las dificultades económicas durante 1954 y la crisis estructural del populismo ibañista terminó con este delicado equilibrio. En efecto, las transformaciones que hemos revisado en este artículo se consolidaron con la elección directiva de SOFOFA de 1955. En dicha elección, Domingo Arteaga, representante de los sectores juveniles, reemplazó a Walter Müller. Terminaban de esta manera 20 años de hegemonía de los sectores más tradicionales en la conducción de SOFOFA.

\section{Bibliografía}

Arriagada, Genaro. Los empresarios y la política. LOM Ediciones. Santiago de Chile, 2004.

Boltanski, Luc y Chiapello, Eve. El Nuevo Espíritu del Capitalismo. Ediciones Akal, S.A. 2002.

Cavarozzi, Marcelo. The government and the industrial bourgeosie in Chile: 1938 - 1964. University of California, 1975.

Correa, Sofía. Con las riendas del poder. La derecha chilena en el siglo XX. Random House Mondadori S.A. Santiago de Chile, 2011.

Couyoumdjian, Juan Pablo. “¿Por qué la misión Klein Saks? Los orígenes de un programa de estabilización económica para Chile" en Juan Pablo Couyoumdjian (Editor). Reformas económicas $e$ instituciones políticas: la experiencia de la misión Klein Saks en Chile. Universidad del

\footnotetext{
${ }^{99}$ Claus Offe. Algunas contradicciones del moderno Estado de Bienestar. Alianza Universidad. Pág. 137.

${ }^{100}$ Fernández y Goldflam, op. cit.
} 
Desarrollo, Santiago, 2011.

Díaz, José; Lüders, Rolf y Wagner, Gert. Chile 1810 - 2010. La República en cifras. Historical Statistics. Ediciones Universidad C atólica de Chile. Santiago, 2016.

Fernández Abara, Joaquín. El ibañismo (1937-1952): Un caso de populismo en la política chilena. Instituto de Historia Pontificia Universidad Católica de Chile. Santiago de Chile, 2007.

Fernández Abara, Joaquín y Goldflam Leiva, Margarita. "Hacia la constitución de una economía de mercados jerárquicos: modernización capitalista y tradicionalismo social en los industriales chilenos (1952 - 1958)". Les Cahiers ALHIM. Partis, mouvements et organisations patronales: les droites dans le Cone Sud Latino- américain (1950 - 2016). № 32, 2016.

Ffrench-David, Ricardo. Chile, entre el neoliberalismo y el crecimiento con equidad. Cuarenta años de políticas económicas y sus lecciones para el futuro. JC Sáez Editor SPA., Santiago, 2014 (Quinta Edición).

Ffrench-Davis, Ricardo. Políticas económicas en Chile, 1952 - 1970. Centro de Estudios de Planificación Nacional. Ediciones Nueva Universidad. Universidad Católica de Chile.

Gamonal, Manuel José. Ernesto Ayala Oliva. Constructor del progreso. Aguilar Chilena de Ediciones S.A. Santiago de Chile, 2012

Gárate, Manuel. La revolución capitalista de Chile (1973 - 2003. Universidad Alberto Hurtado. Santiago de Chile, 2012.

Mardonez Zúñiga, Rodrigo. “Chile y su comercio con Argentina, 1930 - 1960”. Revista Historia. Volumen 29, 1995 - 1996. Instituto de Historia. Pontificia Universidad Católica de Chile.

Montero, Cecilia. La revolución empresarial chilena. Cieplan/Dolmen Ediciones

Moulian, Tomás. El Gobierno de Ibáñez, 1952- 1958. Material docente sobre historia de Chile. Programa Flacso - Santiago de Chile No 2. Enero, 1986.

Moulian, Tomás. Fracturas. De pedro Aguirre Cerda a Salvador Allende (1938 - 1973). LOM Ediciones. Santiago, 2014.

Offe, Claus. Algunas contradicciones del moderno Estado de Bienestar. Alianza Universidad.

Olavarría Bravo, Arturo. Chile entre dos Alessandri. Memorias políticas. Tomo II. Editorial Nascimento. Santiago, 1962.

Pinto, Aníbal. Chile, un caso de desarrollo frustrado. Editorial Universitaria S. A., 1973.

Pizarro, Crisóstomo. La Huelga Obrera en Chile. Ediciones SUR. Santiago de Chile, 1996.

Rubio, Pablo y Salgado, Xaviera. "Gremios empresariales y derecha chilena: Redes de poder y propuestas programáticas de la Sociedad Nacional de agricultura, 1952 - 1958” Les Cahiers ALHIM. Partis, mouvements et organisations patronales: les droites dans le Cone Sud Latinoaméricain $(1950$ - 2016). № 32, 2016.

Undurraga, Tomás. Divergencias. Trayectorias del neoliberalismo en Argentina y Chile, Santiago, Ediciones Universidad Diego Portales, 2014.

Valdés, Juan Gabriel. La Escuela de Chicago: Operación Chile. Buenos Aires, Grupo Zeta, 1989.

Valdivia, Verónica. Nacionales y gremialistas. El "parto" de la nueva derecha política chilena 
1964-1973. Santiago, LOM, 2008.

\section{Fuentes}

Industria. Boletín de la Sociedad de Fomento Fabril, 1950 - 1957

Panorama Económico, 1951 - 1955.

El Mercurio, 1951 - 1955.

El Debate, 19512. 